\title{
SERUM ANTIGLIADIN ANTIBODIES IN EGYPTIAN CHILDREN WITH AUTISM SPECTRUM DISORDER: RELATIONSHIP TO GASTROINTESTINAL SYMPTOMS, BEHAVIORAL AND SOCIAL COMMUNICATIONS
}

\author{
INAS R EL-ALAMEEY ${ }^{1 *}$, HANAA H AHMED ${ }^{2}$, IHAB M EID ${ }^{3}$, GHADA EL-DORY ${ }^{3}$, MANAL GAMEEL ${ }^{4}$ \\ ${ }^{1}$ Child Health Department, National Research Centre, Egypt. ${ }^{2}$ Hormones Department, National Research Centre, Egypt. ${ }^{3}$ Medical Childhood \\ Studies Department, Institute of Postgraduate Childhood Studies, Ain Shams University, Egypt. ${ }^{4}$ Zahira Abdeen Hospital, Ministry of \\ Health, Egypt. Email: inasno@hotmail.com \\ Received: 22 September 2017, Revised and Accepted: 15 January 2018
}

ABSTRACT

Objectives: Gastrointestinal symptoms are major characteristic in children with autism spectrum disorder (ASD), drawing attention to a potent association with gluten sensitivity. The goal of this study was to evaluate anti-gliadin antibodies serum levels in a group of Egyptian children with ASDs and to address the potential link to gastrointestinal (GI) symptoms, behavioral, and social communications.

Patients and Methods: This descriptive case-control study included 45 children diagnosed as ASD according to Diagnostic and Statistical Manual of Mental Disorders $5^{\text {th }}$ Edition and a history of GI symptoms, compared with 45 apparently healthy children of matched age and sex. Serum anti-gliadin antibodies were measured using enzyme-linked immunosorbent assay kits.

Results: Serum levels of IgM, IgA, and IgG class antibodies to gliadin showed a significant increase compared to healthy controls ( $\mathrm{p}<0.000)$. Multiple logistic regression analysis showed a significant association between the high serum levels of IgA and IgM class antibodies to gliadin in the studied patients and GI symptoms $(\mathrm{p}<0.05)$. A significant association was detected between the high serum levels of IgG antibodies to gliadin and the behavior symptoms $(\mathrm{p}<0.05)$.

Conclusions: The anti-gliadin antibody response and its association with GI symptoms indicated the involvement of abnormal immunologic intestinal permeability in affected children. Immune system of some autistic patients could be abnormally triggered by gluten assumption.

Keywords: Autism spectrum disorder, Antigliadin antibodies, Egyptian children, Gastrointestinal symptoms.

(c) 2018 The Authors. Published by Innovare Academic Sciences Pvt Ltd. This is an open access article under the CC BY license (http://creativecommons. org/licenses/by/4. 0/) DOI: http://dx.doi.org/10.22159/ajpcr.2018.v11i4.22723

\section{INTRODUCTION}

Autism spectrum disorder (ASD) is a complex neurodevelopmental disorder characterized by restricted, repetitive patterns of behaviors, interests, and play activities with persistent deficits in social communication and interactions [1]. The overall prevalence of ASD according to latest data from the centers for disease control and prevention was $1 / 88$ children [2]

Gastrointestinal (GI) symptoms are commonly reported by parents of ASD children with a rate of $20-85 \%$. Meanwhile, many of these symptoms are observed in the general pediatric population as well. The most common GI symptoms are chronic constipation, diarrhea, and abdominal pain. Gastroesophageal reflux, bloody stools, vomiting, and gaseousness are also detected in some autistic children as signs of GI inflammation $[3,4]$

A possible association between ASD and non-celiac gluten sensitivity (GS) has been suggested by Grazyna [5]. They mentioned that a state of T-cell immune-mediated chronic small intestinal enteropathy that is stimulated by the intake of gluten proteins in genetically predisposed individual causes impairment of intestinal barrier function and increased gut permeability. The condition continues as long as patients continue to ingest protein.

Other studies suggested the peptides formed through the incomplete breakdown ingested gluten escaped into the circulation and act as exogenous opioids triggers the opioid receptors in the brain with the release of the endorphins and enkephalins (opium-like effect) resulting in lack of attention and communication in those children [6]. Eliminating gluten has shown to be effective in reducing some of the behavioral symptoms of ASD $[7,8]$. Therefore, the aim of our study was to evaluate the antibody response to gluten proteins in a group of Egyptian children with ASD and also to investigate if these antibodies have any relation to their social communications, behavioral, and GI symptoms.

\section{PATIENTS AND METHODS}

Design and setting of the study

This descriptive cross-sectional case-control study was conducted over a period of 1 year. The participants have been regularly attending outpatient Clinic of Center for Care of Children with Special Needs, Institute of Postgraduate Childhood Studies, Ain Shams University, Egypt.

\section{Patients and controls}

The study included 90 children being divided into two groups; 45 children ( 36 boys and 9 girls) with ASD aged 6-12 years with mean of $8.2 \pm 2.4$ years in Group I, and 45 age, sex, and social class comparable apparently healthy children without suggestive history of medical, neurological, or psychiatric disorders in Group II. They were selected from the outpatients' Clinic at National Research Centre, Egypt, while they were coming for follow-up.

Inclusion criteria for selection in Group I included all children with ASD over a period of 1 year. Exclusion criteria included autistic children suffering from an acute or chronic infection or taking drugs affecting gastrointestinal tract. The diagnosis of ASD was established on the basis of medical history, physical examination according to the American Psychiatric Association's Diagnostic and Statistical Manual of Mental Disorders $5^{\text {th }}$ Edition criteria [1]. 
Standard protocol approvals and patient consents

The study was conducted in accordance with the Research Ethics Committee of Institute of Postgraduate Childhood Studies, Ain Shams University, with ethical number 29.6.2010. Written informed consent was obtained from the parents of the participating children.

\section{Methods}

All children were subjected to full detailed history including age and sex of patients, perinatal, postnatal complications and history of behavior disorders, the presence of convulsions, and course of disease, age of beginning of treatment and the treatment regimen, comorbidity, or complications. Inquiring about special diets, a prior of food allergy, types of food selectivity, frequent vomiting, a prior diagnosis of abdominal pain, characteristics of the bowel movements, diarrhea, constipation, use of laxatives or enemas, number of bowel movements per day, and prior visits to a gastroenterologist were evaluated. The parents were asked to complete a questionnaire regarding the child's medical and behavioral history. Through clinical examination include general and systemic examination (chest, heart, and abdomen) and neurological evaluation. The severity of gastrointestinal disturbance was evaluated.

\section{Biochemical measurements}

From all cases, and controls, 5 cc venous blood samples were obtained by venipuncture and collected in plain tubes. The blood samples were allowed to clot at room temperature and then centrifuged for $10 \mathrm{~min}$. Samples were assayed in a single large batch, in duplicate. Antigliadin antibodies (IgA, IgM, and IgG) were measured by an enzymelinked immunosorbent assay using kit purchased from Immunospec Corporation, CA according to the method described by Trocone and Ferguson [9]. The cutoff value was calculated from healthy control samples.

\section{Statistical analysis}

The sample size was calculated to assess of the risk factors probably affecting serum levels anti-gliadin antibodies of children with ASD. Statistical analyses were performed using the SPSS statistical package software for Windows version 22 (SPSS Inc., Chicago, Illinois, USA). Data obtained from the research were organized, tabulated and analyzed through IBM personal computer. Parametric variables are expressed as the mean \pm standard deviation. Differences between parametric variables among the controls and the studied patient's groups were analyzed using two-tailed unpaired t-test. Qualitative variables were assessed by Chi-square test. Multiple logistic regression analysis was calculated for the association between serum antigliadin antibodies to their behavioral, and GIT symptoms. $\mathrm{p}<0.05$ was considered significant difference and $\mathrm{p}<0.01$ was considered the highly significant difference.

\section{RESULTS}

\section{Demographic characteristics of the participants}

A total of 45 children with ASD aged between 6 and 12 years were studied. They were 36 males and 9 females with a male to female ratio 4:1. All patients had been delivered at full-term through normal vaginal delivery. In this study, 21 patients (48\%) had perinatal and postnatal complications in the form of asphyxia (25.7\%), neonatal jaundice in $(11.9 \%)$, head trauma in $(2.2 \%)$, neonatal convulsions in $(2.2 \%)$, and respiratory distress in (4.4\%). Fig. 1 showed perinatal and postnatal complications in the studied patients.

Hyperactivity was present in $70 \%$ patients, epileptogenic focus in $30 \%$ patients, anxiety in $20 \%$ patients, sleep problems in $7.5 \%$ patients, nocturnal enuresis in $15 \%$ patients, encopresis in $5 \%$, self-injurious behavior in $4.4 \%$ patients, and diminished motor power in $2 \%$. Fig. 2 showed behavior and neurological symptoms of the studied patients.

Gastrointestinal symptoms included chronic abdominal pain in 52\%, anorexia in $50 \%$, abdominal distension in $45 \%$, constipation in $40 \%$, diarrhea in $20 \%$, and vomiting in $10 \%$. Fig. 3 showed gastrointestinal symptoms in the studied patients.
The mean serum levels of IgA, IgG, and IgM class antibodies to gliadin were significantly higher in the studied patients group compared to controls $(p<0.05)$. Table 1 illustrated the laboratory findings of the patients under study and the controls.

High serum levels of IgM antibodies to gliadin were present in $86.7 \%$ patients, $20 \%$ patients had high serum levels of IgG antibodies to gliadin, and $37.8 \%$ patients had high serum levels of IgA antibodies to gliadin. Fig. 4 showed the comparison of the laboratory findings of the studied patients group.

Multiple logistic regression analysis showed a significant association between the high serum levels of IgA and IgM class antibodies to gliadin in the studied patients and GI symptoms $(\mathrm{p}<0.05)$. A significant association was detected between the high serum levels of IgG antibodies to gliadin and the behavior symptoms $(p<0.05)$. Tables 2 and 3 showed multiple logistic regression analysis of risk factors such as behavior and gastrointestinal symptoms associated with high serum anti-gliadin antibody of the studied patients.

\section{DISCUSSION}

Gastrointestinal symptoms are common in children with ASD, and its etiology is still not clear whether or not there is a potent association between ASD and GS. Therefore, the aim of our study was to investigate the serological response to ingested gluten through quantification of anti-gliadin antibodies (IgA, IgM, and IgG), and to elucidate if these antibodies have any relation to their behavioral, gastrointestinal signs, and symptoms in our area.

Of a total 45 patients with ASD, more than two-thirds of the children were males $(80 \%)$ with a male to female ratio of $4: 1$. Our finding was in agreement with Abdelaziz [10], who reported that male children

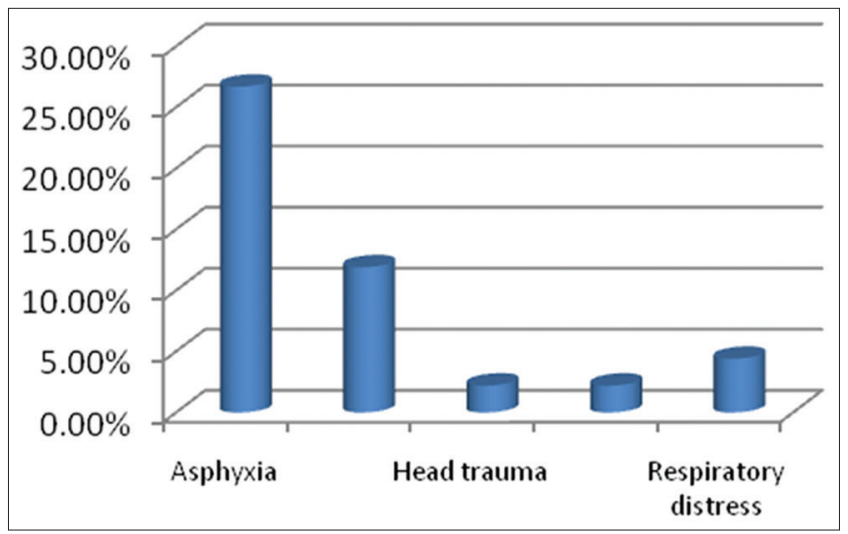

Fig. 1: Perinatal and postnatal complications of the studied patients

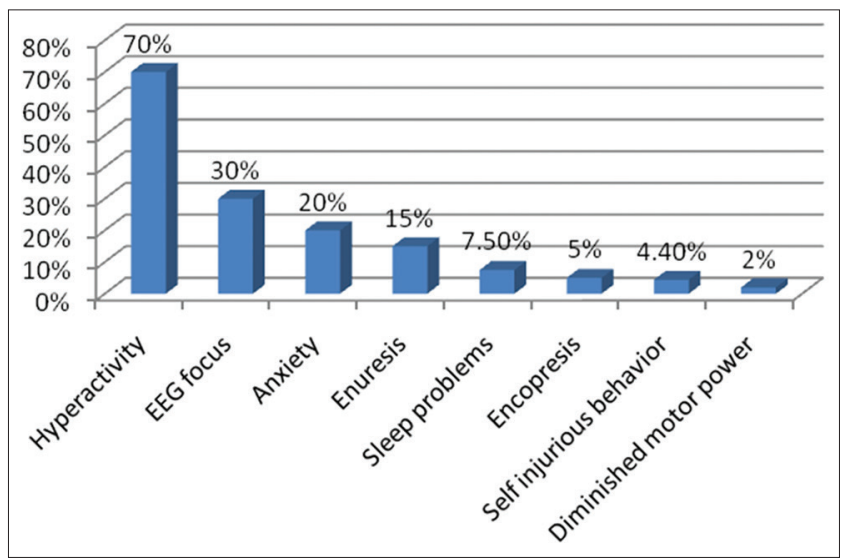

Fig. 2: Behavioral and neurological symptoms of the studied patients 
Table 1: Comparison of the laboratory findings of the studied patients and control groups

\begin{tabular}{|c|c|c|c|c|c|}
\hline Variables & & Cases $(n=45)$ & Control $(n=45)$ & $\mathbf{t}$ & $\mathbf{p}$ \\
\hline \multirow[t]{2}{*}{ Serum anti-gliadin IgA (IU/ml) } & Mean \pm SD & $161.60 \pm 23.65$ & $95.67 \pm 15.89$ & 13.21 & $<0.01$ \\
\hline & Range & $121.34-208.46$ & $67.0-135.4$ & & \\
\hline \multirow{2}{*}{ Serum anti-gliadin IgG (IU/ml) } & Mean \pm SD & $153.02 \pm 31.61$ & $90.20 \pm 80.73$ & 3.35 & $<0.05$ \\
\hline & Range & $108.00-215.98$ & $38.12-445.72$ & & \\
\hline \multirow[t]{2}{*}{ Serum anti-gliadin IgM (IU/ml) } & Mean $\pm S D$ & $2.74 \pm 1.21$ & $0.96 \pm 0.19$ & 9.64 & $<0.01$ \\
\hline & Range & $1.1-5.6$ & $0.79-1.37$ & & \\
\hline
\end{tabular}

Significant difference at $\mathrm{p}<0.05$; highly significant difference at $\mathrm{p}<0.01$. SD: Standard deviation

Table 2: Multiple logistic regression analysis of behavior symptoms associated with high serum anti-gliadin antibody levels among the studied patients

\begin{tabular}{llll}
\hline Variables & B & SE & Significance \\
\hline Constant & -109.6 & 28.56 & $0.00^{* *}$ \\
Serum anti-gliadin IgA antibody levels & 0.929 & 220 & 0.58 \\
Serum anti-gliadin IgG antibody levels & -3188 & 613 & 0.00 \\
Serum anti-gliadin IgM antibody levels & 0.297 & 44.49 & 2.53 \\
\hline
\end{tabular}

Dependent variable: Behavior symptoms. *Significant difference at $\mathrm{p}<0.05,{ }^{* *}$ highly significant difference at $\mathrm{p}<0.01$. SE: Standard error

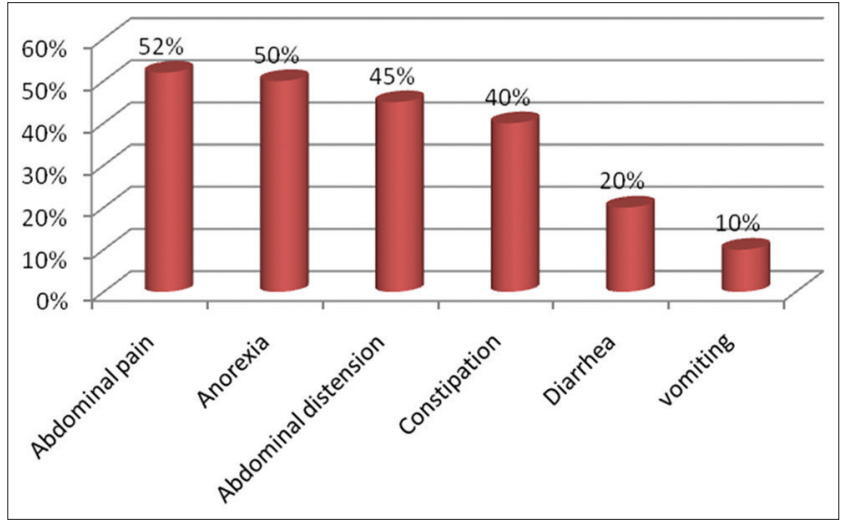

Fig. 3: Gastrointestinal symptoms of the studied patients

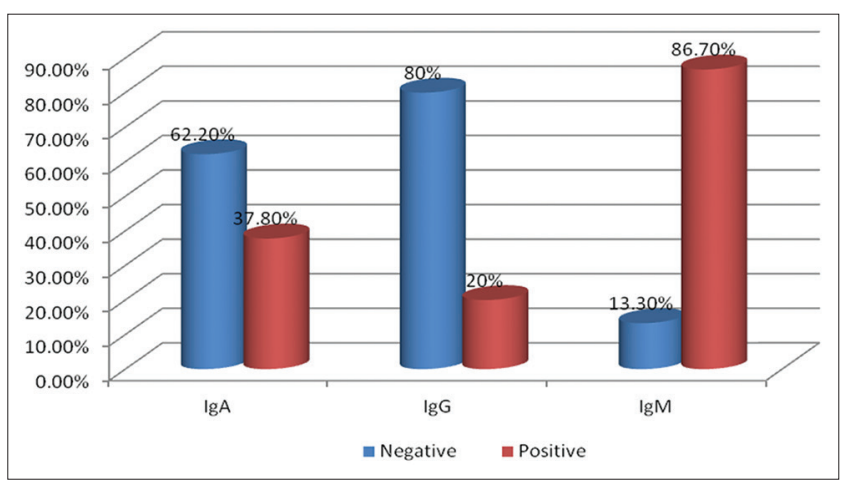

Fig. 4: Comparison of the laboratory findings of the studied patients group

had a higher prevalence rate of ASD than females. In line with the centers for disease control and prevention [2], estimated the number of male to female children with ASD range between 4 and 1 and these gender differences are fairly consistent across ethnicities. The reasons behind the significant increase in the prevalence rate of male children with of ASD are not clear. On the other hand; the study conducted by Schneider [11] found that; the majority of the participants are females (84.6\%), and $7.1 \%$ are males which are not agree with our study.

Kolevzon et al. [12] suggested the presence of nonheritable perinatal and postnatal risk factors for ASD. Furthermore, they demonstrated an association between ASD and obstetric complications. In this study,
21 patients (48\%) had perinatal and postnatal complications in the form of asphyxia in $25.7 \%$, jaundice in $11.9 \%$, head trauma in $2.2 \%$, neonatal convulsions in $2.2 \%$, and respiratory distress in $4.4 \%$.

Our results were in the agreement with Juneja et al. [13] who observed impairment in social interaction and abnormal behavior in children with ASD.

Gluten sensitivity (GS) is a clinical condition in which intestinal and extraintestinal symptoms are caused by gluten consumption, in the absence of coeliac disease. These symptoms are commonly appeared soon after gluten consumption and improved or disappeared within hours or a few days after gluten withdrawal, and then relapsed following its reintroduction [14]. Not only gliadin but also other proteins present in gluten and gluten-containing cereals (wheat, rye, barley, and their derivatives) may have a function in the symptoms development [15]. Prevalence rates of GS are between $0.5 \%$ and $13 \%$ in the general population [16].

Most cases that have GI symptoms paralleled by gluten consumption do nothave celiac disease butrather have a different response to gluten [17]. This may be an allergic response to poor digestion of the product [18]. The determination of GS is regularly identified by improvement in symptoms after stopping of meals containing gluten [19]. GI symptoms include abdominal pain, constipation, and diarrhea. The relatively common problem is the abdominal pain with estimates of occurrence reaching up to $8 \%$ and $30 \%$ in autistic children [20].

In our present study, $60 \%$ had GI symptoms. Our results are in the agreement with Valicenti-McDermott et al. [20], who stated that 70\% of with autistic children had GI problems, while Campbell et al. [21] reported $43 \%$ of children with autism had GI problems. The higher incidence of chronic abdominal pain, anorexia, abdominal distension, and constipation observed in our examined patients, could be attributed to that they are very meticulous eaters with eating problems as most of them refuse to eating fruits and vegetables.

Immunological determination of IgA and IgG antibodies to gliadin is useful initial markers in screening and diagnosis GS. Anti-gliadin IgA antibodies are more specific markers for disease than antigliadin IgG antibodies serving for initial screening, assessing diseases activity, and judging management with a gluten-free diet [22].

To the best of our knowledge, our study is considered to be the first clinical study that measures IgM gliadin antibody response to gluten in ASD children in Egypt and examine their relationship with behavior and GI symptoms. 
Table 3: Multiple logistic regression analysis of GI symptoms associated with high serum anti-gliadin antibody levels among the studied patients

\begin{tabular}{lllll}
\hline Variables & B & SE & Wald & Significance \\
\hline Constant & -10.48 & 3.019 & 12.048 & 0.001 \\
Serum anti-gliadin IgA antibody levels & 0.084 & 0.023 & 13.37 & $0.00^{* *}$ \\
Serum anti-gliadin IgG antibody levels & -347 & 0.372 & 0.868 & 0.352 \\
Serum anti-gliadin IgM antibody levels & 0.013 & 0.005 & 7.661 & 1.088 \\
\hline
\end{tabular}

Dependent variable: GIT symptoms. ${ }^{* *}$ Highly significant difference at $\mathrm{p}<0.01$. SE: Standard error, GI: Gastrointestinal

In our patients, a statistically highly significant rise in serum levels of IgA, IgM, and IgG class of antigliadin antibodies was evidenced in respect with the control group. The present findings fit those of Ludvigsson et al. [23], who reported that GS leads to raised serum level of anti-gliadin IgA and IgG antibodies. Furthermore, Lau et al. [22] said that children suffered ASD with GIT symptoms have been determined to have more frequently higher concentration of AGA-IgG antibodies than healthy peers. The data of our study indicated a link between ASD and increased GS. The ASD children revealed significantly increased IgA, IgG, and IgM anti-gliadin antibody serum levels relative to unrelated healthy counterparts.

Multiple logistic regression analysis showed a significant association between the high serum levels of IgA, and IgM class antibodies to gliadin in the studied patients and GI symptoms $(\mathrm{p}<0.05)$. This is in agreement with Buie [24], who suggested a link between GI symptoms and GS.

Children with ASD may not be capable to explain when they are in pain and can present with problem behaviors as the manifestation of underlying illness [8]. In our present study, a significant association was detected between the high serum levels of $\operatorname{IgG}$ antibodies to gliadin and the behavior symptoms. This is in agreement with Moreno et al. [25] and Francisco [26], who reported that gliadorphin (derived from gluten foods) was recognized in the urine of autistic patients. The incomplete digestion and extra-absorption of gluten peptides may additionally react with opiate receptors in the brain, resulting in neurological alteration that dramatically exacerbate the symptoms of autism. Anxiety, irritability with aggression and sleep disturbance are interconnected to the frequency and severity of GI symptoms in autistic children (Mussel et al., [27]. However, Andreas et al. [28] mentioned no association between gluten and behavior in autistic children, and actually, a gluten-free meal might be another negative factor inducing to further social isolation in this group of highly socially handicapped patients and families.

In our present study, there is a good clinical response to gluten withdrawal when we stop all gluten from their meal and GI symptoms go away. It is an excellent marker that they have GS. This is in agreement with Caio et al. [29], who detected that some cases experience improvements (such as reduction of abdominal pain), which can take 6 months to a year for the small intestine lining to heal completely.

\section{CONCLUSION}

The current data clearly demonstrate that children with ASD have enhanced levels of antibody to gliadin versus healthy controls. The elevated anti-gliadin antibody response to wheat gliadin in ASD and its connection with GI symptoms indicate a potent mechanism involving immunologic and/or intestinal permeability abnormalities, so withdrawing the triggering agents from the meal could be considered as a tool in nutrition therapy for ASD children.

\section{Recommendation}

Every child with ASD and gastrointestinal symptoms should be tested for GS after exclusion of celiac disease.

\section{CONFLICTS OF INTERESTS}

The authors declare that they have no conflict of interest.

\section{REFERENCES}

1. American Psychiatric Association. Diagnostic and Statistical Manual of Mental Disorders. $5^{\text {th }}$ ed. Washington, DC: APA; 2013.

2. Centers for Disease Control and Prevention (CDC): Prevalence of Autism Spectrum Disorders-Autism and Developmental Disabilities Monitoring Network, United States, Morbidity and Mortality, Weekly Report: Surveillance Summaries; 2014;58:1-20.

3. Wasilewska J, Klukowski M. Gastrointestinal symptoms and autism spectrum disorder: Links and risks-a possible new overlap syndrome. Pediatric Health Med Ther 2015;6:153-66.

4. Coury DL, Ashwood P, Fasano A, Fuchs G, Geraghty M, Kaul A, et al. Gastrointestinal conditions in children with autism spectrum disorder: Developing a research agenda. Pediatrics 2012;130:160-8

5. Grazyna CB. Non coeliac gluten sensitivity: A new disease with gluten intolerance. Clin Nutr 2015;34:189-94.

6. de Theije CG, Wu J, da Silva SL, Kamphuis PJ, Garssen J, Korte SM, et al. Pathways underlying the gut-to-brain connection in autism spectrum disorders as future targets for disease management. Eur $\mathbf{J}$ Pharmacol 2011;668 Suppl 1:S70-80.

7. Theoharides TC, Doyle R, Francis K, Conti P, Kalogeromitros D. Novel therapeutic targets for autism. Trends Pharmacol Sci 2008;29:375-82.

8. Bhagat V, Jayaraj J, Haque M. Parent's self-efficacy, emotionality, and intellectual ability impacting the intervention of autism spectrum disorders: A review proposed model for appraisal of intervention. Int J Pharm Pharm Sci 2015;7:7-12.

9. Trocone R, Ferguson A. Anti-gliandin antibodies. J Ped Gastro Nut 1991;12:150-8.

10. Abdelaziz TA. Head-Circumference and Blood Lead Level in Autistic Children, Published Master Degree, Faculty of Medicine, Zagazig University; 2011. Available from: http//www.edu.eul.eg.

11. Schneider T. The Effects of Sex Differences and Cohabitation Status on Parental Stress in Parents of Children Diagnosed with Autism Published Doctoral Dissertation, Philosophy Psychology Department, Walden University; 2010.

12. Kolevzon A, Gross R, Reichenberg A. Prenatal and perinatal risk factors for autism: A review and integration of findings. Arch Pediatr Adolesc Med 2007;161:326-33.

13. Juneja M, Mukherjee SB, Sharma S. A descriptive hospital based study of children with autism. Indian Pediatr 2005;42:453-8.

14. Salvador M, Itziar Z, Amelia M, Agustı'n LG, Maria SV. Evidence of the gluten-free and casein free diet in autism spectrum disorders: A systematic review. J Child Neurol 2014;29:1718-27.

15. Fasano A, Sapone A, Zevallos V, Schuppan D. Non-celiac gluten sensitivity. Gastroenterology (Review) 2015;148:1195-2004.

16. Vriezinga SL, Schweizer JJ, Koning F, Mearin ML. Coeliac disease and gluten-related disorders in childhood. Nat Rev Gastroenterol Hepatol (Review) 2015;12:527-36.

17. Catassi C, Fasano A. Celiac disease. Curr Opin Gastroenterol 2008;24:687-91.

18. Di Sabatino A, Corazza GR. Non-celiac gluten sensitivity: Sense or sensibility? Ann Intern Med 2012;156:309-11.

19. Aziz I, Hadjivassiliou M, Sanders DS. Does gluten sensitivity in the absence of coeliac disease exist? BMJ 2012;345:e7907.

20. Valicenti-McDermott M, McVicar K, Rapin I, Wershil BK, Cohen H, Shinnar S, et al. Frequency of gastrointestinal symptoms in children with autistic spectrum disorders and association with family history of autoimmune disease. J Dev Behav Pediatr 2006;27:S128-36.

21. Campbell DB, Buie TM, Winter H, Bauman M, Sutcliffe JS, Perrin JM, et al. Distinct genetic risk based on association of MET in families with co-occurring autism and gastrointestinal conditions. Pediatrics 2009; $123: 1018-24$

22. Lau NM, Green PH, Taylor AK, Hellberg D, Ajamian M, Tan CZ, et al. 
Markers of celiac disease and gluten sensitivity in children with autism. PLoS One 2013;8:66-155.

23. Ludvigsson JF, Leffler DA, Bai JC, Biagi F, Fasano A, Green PH, et al. The Oslo definitions for coeliac disease and related terms. Gut 2013;62:43-52.

24. Buie T. The relationship of autism and gluten. Clin Ther 2013;35:420-30.

25. Moreno ML, Ángel C, Alba M, Carolina C, Isabel C, Ángeles P, et al. Detection of gluten immunogenic peptides in the urine of patients with coeliac disease reveals transgressions in the gluten-free diet and incomplete mucosal healing. Gut 2017;66:250-7.

26. Francisco L. Gluten Peptides in Urine Correlate with Mucosal Damage in Celiac Disease; 2016

27. Mussel M, Kroenke K, Spitzer RL, Williams JB, Herzog W, Lo“we B. Gastrointestinal symptoms in primary care: Prevalence and association with depression and anxiety. J Psychosom Res 2008;64:605-12.

28. Andreas R, Joachim H, Ewelina MG, Loredana T, Klaus WL. Glutenfree and casein-free diets in the treatment of autism. Funct Foods Health Disease 2014;4:349-61.

29. Caio G, Volta U, Tovoli F, De Giorgio R. Effect of gluten free diet on immune response to gliadin in patients with non-celiac gluten sensitivity. BMC Gastroenterol 2014;14:26 